\title{
The Influence of New Media on University Students' Time Anxiety
}

\author{
Leishan Deng ${ }^{1 *}$ \\ ${ }^{1}$ School of Foreign Studies, Wenzhou University, Wenzhou, 325000, China \\ *Corresponding author's Email: 2503095475@qq.com
}

\begin{abstract}
Because the psychology of the college students who grew up in the new media era is still in the developing stage, they are easily affected by the content on the media platform, resulting in time anxiety. Starting from the social and personal level, this paper studies the relationship between college students' time anxiety and new media, summarizes the specific impact of new media on it and the reasons for this impact, and proposes to improve the status, that is college students improve their ability to discriminate information, society respects individual differences, and media platforms strengthen information supervision.
\end{abstract}

Keywords: Time anxiety, New media, College students.

\section{INTRODUCTION}

With the advancement of society and the development of Internet technology, the number of Chinese netizens has been increasing, and the amount of time spent on the Internet per capita has gradually increased. According to the 45th "Statistical Report on China's Internet Development Status" released by the China Internet Network Information Center, as of March 2020, the number of Chinese Internet users has reached 904 million. Among them, the number of teenager Internet users reached 277 million, accounting for $79.6 \%$ of the total teenager population in China. In the age structure of domestic Internet users, people of 20-29 years old account for the largest proportion, as high as $21.5 \%$. Statistics on the occupational structure of netizens show that students account for the highest proportion of all netizens, at $26.9 \%$. The average weekly online time per netizen has also increased from 27.9 hours in 2019 to today's 30.8 hours. It shows that the Internet has a great influence on contemporary young students, especially college students. According to statistics from the "2020 China University Student Employment Report", from the perspective of expected employment cities, well-known companies in first-tier, new-tier cities and some provincial capital cities have become the first choice for graduates; because of the increasing uncertainty in the economic situation in recent years, some traditional recruiters all have reduced the scale of recruitment, so the competition that graduates will face is relatively fierce. The "Report" also pointed out that because the postgraduate entrance examination played a role in diversion and buffering of the employment of college students, the proportion of graduated who entered a higher education continued to rise, so the difficulty of college students' entrance examinations has only increased. In order to improve their core competitiveness, college students have long been in a state of tension that they want to plan their time perfectly, make full use of their time and worry about wasting time; the rapid changes in modern society and the continuous acceleration of people's life rhythm also cause people to always worry about being behind the world. The new media environment provides people with diversified information release platforms. However, some self-media deliberately overstated facts and exaggerated nervousness in order to grab attention and obtain economic benefits. When college students are affected by these contents, they will have a sense of uncertainty about the future, thereafter fell into the group panic of time anxiety. This kind of anxiety gradually breeds and spreads and becomes an important factor affecting the life, study and work of college students. Therefore, this paper will focus on the influence of new media on college students' time anxiety.

\section{BACKGROUND}

\subsection{Researches on time anxiety}

The scholar Zhang Bo starts from the perspective of individual time utilization, and defines time anxiety as: a 
state of tension in which time is planned reasonably, time is fully utilized, and time cannot be wasted, and the resulting behavioral manifestations and tendencies[1]. In addition to the passivity that has to be accelerated due to time constraints, it also contains an initiative that generates tension and anxiety due to the need to plan and use time rationally. This definition systematically expounds the characteristics of modern people's time anxiety, but does not analyze its causes.

Many scholars have conducted research on the causes of time anxiety. The research mainly focuses on media technology and the acceleration of social rhythm. Scholars Chen Lidan and Mao Zhanwen believe that new media technology has a great influence on the generation of time anxiety, and pointed out that time and space tension is the confused psychological tension that is caused by the impact of new media technology and feels that time is not enough[2]. The information overload caused by the interface of the new media terminal distracts our attention, and also brings about the decentralization of dissemination and the break of time and space. Wang Haifeng believes that in addition to media technology, the content published on the media also has a certain impact[3]. In recent years, various platforms have promoted a view of using time as a usable resource, so people gradually feel that time is not enough, resulting in stress and tension, and some physical and psychological reactions and symptoms.

From a macro perspective, the scholar Chen Changkai analyzes from the social level, and believes that the rapid changes in modern society have led to the extreme expansion of young people's expectations, but at the same time they are squeezed by the uncertainty brought about by the rapid changes in society, and finally formed such time anxiety[4]. Wu Lin Lin believes that the social acceleration in the modernization process has brought about the continuous acceleration of people's life rhythm[5]. It is this fast rhythm that presses people, making them spend less time eating, sleeping and restoring their bodies, bearing the anxiety of being "behind" in this world.

\subsection{Researches on new media}

Scholar Li Yong defined new media as "new media that rely on digital technology, internet technology, and mobile communication technology to provide information services to audiences"[6]. Changes in information dissemination under the new media environment are mainly reflected in the following aspects: First, the autonomy and participation of the main body. In the new media era, the dominant mode of dissemination is broken. The users of the media are also the creators and producers of information. The second is the immediacy and massiveness of content. With the rapid development of mobile Internet and mobile terminals, the dissemination and circulation of information has become more free, and the amount of information has become increasingly complex. The third is the fragmentation and virtuality of the context. People gain more self-satisfaction and make more individual decisions on the new digital communication platform. At the same time, the virtuality of the communication relationship and the concealment of personal identity are both for both parties. Conditions are provided for freely publishing or accepting information. In the past, criticisms of people's over-reliance on the media mainly focused on the direct impact of media content or people's behavior on individuals, and seldom considered its connection to more problems from a broader perspective, such as the current anxiety that prevails among college students. To a large extent, their anxiety is closely related to society's over-reliance and trust towards the media, which is worthy of our further study.

\section{MANIFESTATION OF TIME ANXIETY}

\subsection{Appropriate anxiety level can stimulate learning motivation}

Psychological research by psychologists Yerkes and Dodson has shown that moderate-intensity motivation is most conducive to the completion of the task. When the motivation intensity is at a medium level, the work efficiency is the highest; once the motivation intensity exceeds this level, it will hinder behavior to a certain extent. Therefore, the appropriate anxiety caused by the new media can actually be transformed into the motivation of college students to face themselves and start acting. On the one hand, college students are a group that has received higher education, and most of them have received psychological studies, so they also have a certain understanding of ways to relieve anxiety. On the other hand, most college students have plans and pursuits for their future life, so they will not let themselves go and fall for themselves, but will take a correct view of the passage of time, actively seek changes, and make full use of time.

\subsection{Excessive anxiety causes low mobility}

College students living in the new media era are exposed to the media environment all the time, because their work, study, and communication can only be realized through the Internet. Facing the heavy academic pressure and the relaxed and happy online world, people need a strong willpower to resist the temptation and interference of the media, and most people do not have this firm will, so they often make the wrong choice, and thus a lot of time is wasted on meaningless online entertainment.

The Yerkes-Dodson law shows that the relationship between motivation intensity and work efficiency is not a linear relationship, but an inverted U-curve relationship. There is an optimal level of motivation for various 
activities. Insufficient or overly strong motivation will lead to a decrease in work efficiency. When faced with task deadlines and final tests, due to tight time and heavy tasks, the pressure on college students is also increasing. They are eager to achieve excellent results, but their motivation is too strong, which leads to unbearable pressure. When the pressure reaches a certain level, it causes their escape psychology, so they choose to engage in retaliatory entertainment at this moment, so as to obtain a temporary sense of happiness in the Internet world. But when they have to get out of their comfort zone, the greater pressure and anxiety will overwhelm them and plunge them into a vicious circle of low mobility.

\section{THE INFLUENCE OF NEW MEDIA ON COLLEGE STUDENTS' TIME ANXIETY}

\subsection{The impact of new media technology on traditional time concepts}

The continuous development of media technology has constantly impacted people's traditional time concept. The time concept formed in the past society is difficult to match with the accelerating social reality of today, and people's anxiety is also generated from this. For example, in the past, observing the movement of stars was a slow and difficult process, requiring observers to wait sleeplessly for a night; but now, we can record videos through media devices and accelerate them, making the whole process very fast. For another example, in the past, people needed to spend a long time to communicate with each other by sending letters; but mobile phones, computers, tablets and other devices make people's communication extremely fast.

In such a social environment, people's concept of time has quietly changed, and they have been working hard to find more efficient ways of living and working. This kind of pursuit of high-speed time concept has made people's sense of time tension constantly strengthened. In order to better adapt to this society, everyone is racing against time and under the pressure of lagging behind the pace of the times. The group of college students seems to have ample free time at their disposal, but when their life time is divided into task time by new media technology, their lives will be dominated by tasks, which will lead to anxiety and panic caused by time constraints.

\subsection{New media has become a hotbed for creating and spreading anxiety}

Due to the autonomy and participation of the We Media, everyone has the opportunity to publish and disseminate opinions on the Internet, the threshold for information dissemination has been greatly reduced, and the authenticity of the information has become worrying. Today's We Media profit model is relatively simple, mostly relying on advertising soft articles for profit, so their purpose of publishing content is to attract more fans and get more clicks. In order to earn more clicks, they disregarded the sense of social responsibility they should be shouldering, and just reposted, exaggerated and made up their opinions, so as to attract people's attention and clicks to obtain economic benefits. In addition, the content that people publish on platforms such as WeChat Moments, Qzone, and Weibo will also inadvertently affect people around them. For example, sharing one's excellent grades, work pressure, study schedule, etc. in the circle of friends may also have a negative impact on others, and this negative emotion will be further spread among friends. Most of the college students live on campus for a long time. They don't have sufficient social experience and lack of understanding of future jobs. Therefore, they are susceptible to anxiety due to the influence of online media.

\subsection{College students'over-reliance on the media}

Nowadays, college students have grown up in the new media environment, and new media has subtly affected their daily life, work and study. People use apps on their smart phones to order food, communicate with people through social software, and study and work through online videos and e-books. It seems that all their daily needs can be solved through new media, and thus college students are becoming more and more dependent on media.

In addition, the Internet is full of all kinds of content, which has a strong impact on people's hearing and vision; the Internet makes it easier for people to get the information they need, and to interpret the connotation behind certain words more quickly; The Internet also provides people with diversified and convenient entertainment methods, taking up all the fragmented time of people. Because college students have a strong thirst for knowledge and still lack a certain degree of selfdiscipline ability, they are very easy to indulge in new media, and this indulgence will cause them to misjudge the time and delay the task. Many college students are accustomed to making a task list before doing things and planning the time to complete each task according to their own predictions. However, due to the interference of network information, they always click into a topic of interest when searching for information, and then find it difficult to extricate themselves; or receive information from others in the middle of the task, and then naturally start a dialogue and delay the task.

\section{SUGGESTION ANALYSIS}

\subsection{College students need to improve their ability to discern information.}

Rogers, a well-known American humanist psychologist, believes: "The root cause of psychological disorders lies in the individual's ingestion and 
internalization of a large number of environmental values during his growth." The psychological development of college students is not mature enough. In the critical period of the formation of outlook on life, world outlook and values, they are extremely dependent on and concerned about the novel and interesting content in the new media age. They are accustomed to looking for the basis for behavior judgment on new media platforms, such as selecting the book they want to read based on the required reading list summarized by others on the Internet, choosing the restaurant to eat based on the score on the software, and easily defines the character of some public figures merely according to the netizen's response. They are extremely easy to be affected by anxious and inflammatory content on the Internet and lose their own judgment.

In order to improve the ability of information screening, college students should actively participate in social practice, improve their own experience, and have the ability to distinguish false information after accumulating a certain amount of experience. At the same time, college students should also continue to acquire knowledge to build self-confidence, neither overly devalue nor over-exaggerate their value, and treat life, study and work issues with a calm and rational mind, so as to avoid being negatively affected by media platforms and correct bad mentality in time.

\subsection{Society increases tolerance for individual differences}

In today's society, people seem to equate success with wealth. The media touts those who have achieved career success at a relatively young age, and wealth has become a constant pursuit of people. Affected by this trend, college students also regard achieving material success as soon as possible as their goal. But while setting goals for themselves, they also narrowed their horizons and rubbed shoulders with many beautiful things on the way. Therefore, their lives are full of pressure and competition, and they are troubled by time anxiety all day long and cannot plan their life reasonably and enjoy their life. Just as Picasso said, "Once you really figure out what you desire, then you can only get so much in this life." Every individual has his own unique advantages. Therefore, our society should discover and respect the multiple possibilities of each individual, so that everyone can show their talents, instead of just defining success as being rich.

\subsection{Media platforms strengthen supervision}

In the era of new media, the threshold for publishing and disseminating information has been greatly reduced. More and more companies and individuals have seized this opportunity and poured into self-media platforms in large numbers. However, due to inadequate platform supervision and low user awareness, the quality of information people obtain from media platforms varies, and it is even difficult to distinguish between true and false. The We Media platform has major flaws in the supervision of whether the account information publisher is the registered subject. The platform will not actively verify the authenticity and security of the content posted by the account, but will rely on users to report. As a result, a large number of soft pornographic, soft violent content, or sales of anxiety and false propaganda content are rampant on We Media platforms. This situation has caused a lot of trouble for users.

To solve this problem, the most fundamental thing is for media operators to increase their awareness, professional ethics and social responsibility. They should realize that if they are not changed, the chaos on the selfmedia platform will only intensify, and they themselves will eventually suffer. The self-media platform itself and the network supervision department also need to strengthen the supervision of network information. The media access threshold should be raised, the rectification efforts should be strengthened, the network "blacklist" system should be established, and the entry prohibition system should be implemented for publishers who have repeated problems. Only in this way can we completely cut off the gray industrial interest chain and purify the networked social environment.

\section{CONCLUSION}

The rapid development of the Internet and the media and the acceleration of the social rhythm have caused tremendous changes in contemporary people's lives. People's traditional concept of time has been greatly impacted. Many people, especially college students, have had problems with the status quo in the new media era. Future confusion and time anxiety. This article studies the relationship between college students' time anxiety and new media, and summarizes the positive and negative effects of new media on college students, that is, appropriate anxiety can stimulate college students' learning motivation, and excessive pressure makes it fall into a vicious circle of low mobility. There are three reasons for this performance. The first is the mismatch between traditional time concepts and social reality, the second is the exaggerated negative information on the media platform, and the over-reliance of college students on the media. In order to improve this situation, college students themselves should improve their ability to discern information. In addition, society should respect individual differences, and media platforms should strengthen the supervision of online information. Only when the psychological quality of college students is improved, and the social and media environment is also improved, can new media have a positive impact on the lives of college students. 
However, there are still shortcomings in this article, for example, the research group is limited to college students. Due to the improvement of people's living standards, multimedia users have tended to be younger in recent years. Many primary and middle school students have had many opportunities to contact new media, and their psychology has been affected to a certain extent. In future research, we should pay attention to a wider range of people, intervene in the psychology of media users as early as possible, and ensure that their mental health is not affected by the redundant information on the Internet. The ultimate goal of raising the problem is to solve the problem, so the research in this area is still worthy of our continued attention.

\section{REFERENCES}

[1] Zhang Bo. Interpretation of the phenomenon of "Shouting baldness" among post-90s youth from the perspective of time anxiety [J]. Journal of Youth and Adolescence,2019(01):3-8.

[2] Chen Lidan, Mao Zhanwen. Space-time tension: Another consequence of the impact of new media on life [J]. Journalists,2014(01):66-71.

[3] Wang Haifeng. The Reality, Media Presence and Countermeasures of Youth Time Anxiety -- Based on the "Post-90s (Post-80s) Have Been... Chinese Youth Studies,2019(03):86-90+113. (in Chinese)

[4] CHEN Changkai. Time Anxiety: Young People under Rapid Social Change. Nanjing Social Sciences, 2016(02):71-76.

[5] Wu Linlin. Status quo and guidance of youth social mentality in new media era [J]. Party History Exposition (Theory),2017(11):57-60.

[6] Li Yong. On the Form and Characteristics of New Media Culture [J]. Journalism,2011(05):99-102. 